\title{
Factors Affecting the Professionalism of Midwifery Students
}

\author{
Sukran Ozkahraman-Koc \\ Suleyman Demirel University, Faculty of Health Science, \\ Department of Midwifery, 32260, Cunur/Isparta, Turkey, \\ E-mail: sukranozkahraman@sdu.edu.tr
}

This study was presented as verbal statement in the 1st International Midwifery Education and Research Development Congress (November 7-9, 2018 - Izmir).

\begin{abstract}
Objective: This descriptive study was conducted to analyze the occupational professionalism of midwifery students and the factors affecting this professionalism. Method: All students in the Department of Midwifery of a healthcare sciences faculty between October 10, 2017 and December 10, 2017 , were included in the study. The sample was formed by 196 students from $2^{\text {nd }}, 3^{\text {rd }}$, and $4^{\text {th }}$-year students. Personal Information Form and Inventory of Professional Attitude at Occupation (IPAO) were used in collecting data for the study. Results: In the study, the mean age of the students was $22.14 \pm 1.36$ and the mean IPAO score of the students was $146.82 \pm 12.00$ (32-160). It was found that there was a statistically significant difference between IPAO mean scores based on the grade level of the students, their reasons for choosing the occupation, and whether the occupation was appropriate for the student ( $p$ $<0.05$ ). Conclusion: It is necessary that adequate information is given to prospective university students regarding the midwifery occupation. It is recommended that midwifery students receive information regarding occupational professionalism throughout their education.
\end{abstract}

Keywords: Midwifery, student, professionalism, occupational professionalism

DOI: $10.7176 / J S T R / 5-2-06$

\section{Introduction}

One of the most important topics for society nowadays is professionalism. Professionalism came to the fore particularly in this century and gained more importance. Professionalism represents a prominent level of expertise, knowledge, ability, attitude, and behavior in a field. Developments until now show new approaches in every field. From here, professionalism is a type of opinion and behavior that must be embraced and accepted by everyone with duty at any level in society, including all employees. (Gökçora, 2005). Moreover, professionalism reminds us of the service provided by people who are experts in their field and presented by the support of occupational organizations. Trying to reach a better level and showing uniqueness also show professionalism (Adıüzel, 2011).

The elements of professionalism are autonomy, knowledge, and a high level of sense of responsibility in serving society. (Seçer, 2009) Professional people are expected to be rational and competent in applications and to behave ethically by making evaluations without ignoring the needs of those who are likely to be affected by a societal rule (Orak, 2012) Thus, people who are professionals in their occupation are shown respect by society and by those in other disciplines (Karadağ, 2004). Reaching the professional status is accepted as an important success in all disciplines, and occupational professionalism is particularly important in the formation of occupational standards and providing quality service (Kacaroğlu Vicdan 2010) (Karadağ and Hisar, 2004). Societal change and technological developments in the recent period make occupational professionalism a requirement. Occupational professionalism, which has a major place in the determination of occupational standards and increasing the quality of services, is the substitution of personal professionalism with organizational professionalism (Adigüzel, 2011) For an occupation to become professional and provide high-quality service to society, professional identities of the members of the occupation must be strong. (Sabancioğullar1, 2012). Midwives are not

55 | P a g e

www.iiste.org 
only important for women but also important for society and family. They have important roles during the pregnancy period, at birth, and after birth in the care of the mother and the baby, in preparation for parenthood, and the development of public health concerning the issues of reproductive health and sexuality (Halldorsdottir, 2011). Factors that midwives need to deal with, such as varying working conditions and working under significant levels of stress, show that the midwifery occupation requires professionalism (Adigüzel, 2011). It has been underscored that members of the occupation must begin their work to acquire a professional identity during their time as students (Secrest, 2003). The recent organization of the midwifery occupation, the determination of ethical values, and the start of doctoral studies have brought the concept of professionalism into midwifery. A professional midwife is knowledgeable, trustworthy, experienced, respectful, empathetic, correct, joyful, sincere, and caring toward privacy and justice (Ergin, 2011). The high number of midwifery schools and students in Turkey and the scarce number of application fields is an important problem encountered in the professionalism of the midwifery occupation (Güner, 2015). On the other hand, technological and political developments direct the traditional midwifery model in the healthcare field toward professionalism (Karaman, 2015). The factors negatively affecting the midwives' becoming professional in Turkey can be counted as not having a standard education, problems in legal regulations, the small number of members at associations, problems encountered at the workplace, and the late start of research studies. This study was planned to contribute to the professionalism of the midwifery occupation, considering the lack of studies in this field. This study was conducted to determine the occupational professionalism of the students and the factors affecting their occupational professionalism.

\section{Materials and Methods}

The universe of this descriptive study was formed by the students studying in the Department Midwifery at a healthcare sciences faculty between October 10, 2017, and December 10, 2017. A total of 196 students who agreed to participate in the study formed the sampling group. Personal Information Form and Inventory of Professional Attitude at Occupation (IPAO) developed by the researcher were used in collecting data for the study. Personal Information Form consisted of the sociodemographic characteristics of the student-midwives (age, family type, graduated high school, where they lived with their family, etc.) and their thoughts regarding the occupation and included 18 questions. IPAO was developed by Erbil and Bakir (2009). The time needed to complete this inventory is $8-10$ minutes. The inventory consists of questions that address attitudes on issues such as occupational education and development, interpersonal relationships, and dealing with problems. In the Likert-type scale, each statement is scored from 5 to 1 . In each statement " 5 " is given to "fits me completely," "4" is given to "fits me a little bit," " 3 " is given to "undecided," "2" is given to does not fit me," and " 1 " is given to "doesn't fit me at all" responses. The lowest possible score from the inventory is 32, and the highest possible score is 160 . The overall score of the inventory is the occupational professional attitude score. An increase in the score shows an increase in the professionalism attitude, and a decrease in the score shows a decrease in professionalism. The alpha reliability coefficient of the scale was 0.89 (Erbil and Bakır, 2009). The alpha reliability coefficient of the scale in our study was found to be 0.82 . A total of 10 midwifery students were asked to fill in the survey to see whether the form developed by the researcher was comprehensible. We decided to use the survey form without any changes. Information gathered from this pre-interview was not included in the study. Informed consent forms were taken verbally after information was given to the students regarding the study and the survey forms were collected during face-to-face interview sessions. Data were evaluated in SPSS 16.0, and numbers, percentage distributions, $t$-tests, and ANOVA tests were used. The statistical significance level was taken as $\mathrm{p}<0.05$.

\section{Results}

We found that the mean age of the midwifery students included in the study was $22.14 \pm 1.36$, the mean IPAO score was $146.82 \pm 12.00$ (32-160), $47.4 \%$ of the students graduated from a super high school, $53.0 \%$ had a nuclear family, the mothers of $43.9 \%$ and the fathers of $53.0 \%$ were primary school graduates, $43.9 \%$ lived in dorms/hostels, $87.7 \%$ indicated their income status as being in the middleincome level. There were 65 midwifery students included in the study who were $2^{\text {nd }}$ and $3^{\text {rd }}$-year students and 66 who were $1^{\text {st }}$-year students. The distribution of IPAO scores according to the personal characteristics of the students is presented in Table 1.

56 | P a g e 
Table 1. The distribution of IPAO scores according to the personal characteristics of the students ( $\mathrm{n}=196)$

\begin{tabular}{|c|c|c|c|c|}
\hline \multirow[t]{2}{*}{ Personal Charecteristics } & \multirow[t]{2}{*}{ Number } & \multirow[t]{2}{*}{$\%$} & \multicolumn{2}{|c|}{ IPAO } \\
\hline & & & Mean \pm SS & $\mathbf{p}$ \\
\hline \multicolumn{5}{|l|}{ Age Group } \\
\hline $19-22$ & 147 & $\% 75$ & $147.44 \pm 12.34$ & \multirow{2}{*}{$\begin{array}{l}Z=-18,952 \\
p=0.00\end{array}$} \\
\hline $23-27$ & 49 & $\% 25$ & $127.52 \pm 11.00$ & \\
\hline \multicolumn{5}{|l|}{ Class } \\
\hline II.Class & 66 & 33.6 & $132.66 \pm 18.97$ & \multirow{3}{*}{$\begin{array}{l}F=6.431 \\
p=0.00\end{array}$} \\
\hline III. Class & 65 & 33.2 & $139.22 \pm 10.56$ & \\
\hline IV. Class & 65 & 33.2 & $147.47 \pm 11.12$ & \\
\hline \multicolumn{5}{|l|}{ Family Type } \\
\hline Nuclear Family & 104 & 53.0 & $144.27 \pm 12.71$ & \multirow{3}{*}{$\begin{array}{l}\mathrm{KW}=1.124 \\
\mathrm{p}=0.45\end{array}$} \\
\hline Extended Family & 22 & 11.3 & $146.21 \pm 10.11$ & \\
\hline Shredded Family & 70 & 35.7 & $143.17 \pm 11.24$ & \\
\hline \multicolumn{5}{|l|}{ She lives with parents } \\
\hline Province & 94 & 47.9 & $147.14 \pm 10.12$ & \multirow{3}{*}{$\begin{array}{l}F=5.165 p= \\
0.03\end{array}$} \\
\hline District & 70 & 35.7 & $132.66 \pm 15.37$ & \\
\hline Town & 32 & 16.4 & $105.28 \pm 20.79$ & \\
\hline \multicolumn{5}{|l|}{ Graduated High School } \\
\hline General High School & 52 & 26.5 & $141.87 \pm 11.25$ & \multirow{3}{*}{$\begin{array}{l}F=1.438 \\
p=0.42\end{array}$} \\
\hline Super High School & 93 & 47.4 & $147.21 \pm 10.02$ & \\
\hline Anatolian High School & 51 & 26.1 & $144.25 \pm 13.24$ & \\
\hline \multicolumn{5}{|l|}{ Income Level Perceived } \\
\hline Good & 8 & 4.2 & $122.64 \pm 11.62$ & \multirow{3}{*}{$\begin{array}{l}K W=28,655 \\
p=0.00\end{array}$} \\
\hline Middle & 172 & 87.7 & $143.68 \pm 13.51$ & \\
\hline $\mathrm{Bad}$ & 16 & 8.1 & $94.41 \pm 21.26$ & \\
\hline
\end{tabular}

In the study, no statistically significant difference was detected between the occupational professionalism attitudes of the students according to their family types and the high school from which they graduated $(\mathrm{p}>0.05)$. A statistically significant difference $(\mathrm{p}<0.05)$ was found between the occupational professionalism attitudes of the students according to their age group, years in school, where they lived with their family, and perceived income level (Table 1).

Table 2 shows the distribution of IPAO scores of the students according to their attitudes toward the occupation. When the perceptions of student-midwives toward the occupation was examined, it was found that $26.7 \%$ chose midwifery as their $2^{\text {nd }}$ and $3^{\text {rd }}$ choice, none chose it as their first choice, $18.5 \%$ did not find the occupation appropriate for themselves, $52.0 \%$ chose the occupation for the opportunity of easily finding a job, $26.5 \%$ would not want to choose midwifery if they had the chance to choose again, $56.1 \%$ wanted to choose an occupation other than midwifery, $15.0 \%$ had positive opinions regarding midwifery before starting training, $85.0 \%$ had positive opinions about midwifery after starting training, and $43.9 \%$ did not want to work as a midwife after graduation (Table 2).

No statistically significant difference was found between the occupational professionalism attitudes of the midwifery students according to their wish to choose another occupation, the order in which they chose midwifery, attitude toward the midwifery occupation before beginning training, and their 
willingness to work as a midwife after graduation $(\mathrm{p}>0.05)$. On the other hand, a significant difference $(\mathrm{p}<0.05)$ was found between the occupational professionalism attitudes of the midwifery students according to the reason for which they chose the occupation, whether they found the occupation appropriate for themselves, and their overall approach toward the occupation after the start of training (Table 2).

Table 2: The distribution of IPAO scores of the students according to their attitudes toward the occupation $(\mathrm{n}=196)$

\begin{tabular}{|c|c|c|c|c|}
\hline \multirow[t]{2}{*}{ Consideration for The Profession } & \multirow[t]{2}{*}{ Number } & \multirow[t]{2}{*}{$\%$} & \multicolumn{2}{|c|}{ IPAO } \\
\hline & & & Mean \pm SS & $\mathbf{p}$ \\
\hline \multicolumn{5}{|c|}{ Department of Midwifery Preference Order } \\
\hline $1-5$ & 52 & 26.7 & $144.65 \pm 15.23$ & \multirow{4}{*}{$\begin{array}{l}\mathrm{KW}=1.216 \\
\mathrm{p}=0.31\end{array}$} \\
\hline $6-10$ & 11 & 0.4 & $144.61 \pm 12.13$ & \\
\hline $11-15$ & 33 & 16.8 & $145.79 \pm 10.24$ & \\
\hline 16 ve üzeri & 110 & 56.1 & $140.75 \pm 12.05$ & \\
\hline \multicolumn{5}{|l|}{ Reason for Choosing The Profession } \\
\hline Finding an easy job & 102 & 52.0 & $147.27 \pm 12.13$ & \multirow{3}{*}{$\begin{array}{l}\mathrm{KW}=14.312 \\
\mathrm{p}=0.00\end{array}$} \\
\hline Family's request & 29 & 14.7 & $135.57 \pm 14.42$ & \\
\hline Stay idle & 65 & 33.1 & $135.62 \pm 16.78$ & \\
\hline \multicolumn{5}{|c|}{ Request to Choose Another Profession } \\
\hline Yes & 110 & 56.1 & $144.71 \pm 13.12$ & $\mathrm{t}=0.207$ \\
\hline No & 86 & 43.9 & $145.68 \pm 11.14$ & $\mathrm{p}=0.25$ \\
\hline \multicolumn{5}{|c|}{ The Willingness to Re-choose Midwifery } \\
\hline Yes & 48 & 73.5 & $145.67 \pm 13.40$ & \multirow{2}{*}{$\begin{array}{l}\mathrm{t}=2.317 \\
\mathrm{p}=0.01\end{array}$} \\
\hline No & 52 & 26.5 & $135.72 \pm 15.63$ & \\
\hline \multicolumn{5}{|l|}{ Profession Finding Status } \\
\hline Very suitable & 66 & 33.6 & $147.67 \pm 12.14$ & \multirow{3}{*}{$\begin{array}{l}\mathrm{KW}=15.614 \\
\mathrm{p}=0.00\end{array}$} \\
\hline Appropriate & 94 & 47.9 & $146.32 \pm 11.65$ & \\
\hline Inappropriate & 32 & 18.5 & $131.76 \pm 19.86$ & \\
\hline \multicolumn{5}{|c|}{ The View of The Profession Before Starting Training } \\
\hline Positive & 30 & 15.0 & $145.37 \pm 12.17$ & \multirow{3}{*}{$\begin{array}{l}\mathrm{KW}=2.425 \\
\mathrm{p}=0.27\end{array}$} \\
\hline Partly positive & 102 & 52.0 & $144.67 \pm 15.22$ & \\
\hline Immortal & 64 & 33.0 & $145.66 \pm 17.28$ & \\
\hline \multicolumn{5}{|c|}{ The View of The Profession After Beginning Education } \\
\hline Positive & 166 & 85.0 & $148.77 \pm 11.13$ & \multirow{3}{*}{$\begin{array}{l}K W=15.614 \\
p=0.00\end{array}$} \\
\hline Partly positive & 17 & 8.6 & $136.82 \pm 12.25$ & \\
\hline Immortal & 13 & 6.4 & $92.36 \pm 13.46$ & \\
\hline \multicolumn{5}{|c|}{ Working Status as Midwife After Graduation } \\
\hline Yes & 86 & 43.9 & $145.81 \pm 12.17$ & $\mathrm{t}=0.312$ \\
\hline No & 110 & 56.1 & $146.78 \pm 14.18$ & $\mathrm{p}=0.14$ \\
\hline
\end{tabular}

58 | P a g e

www.iiste.org 


\section{Discussion}

In this study conducted for the purpose of examining the occupational professionalism and the factors affecting the occupational professionalism of midwifery students, it was found that a quarter of the students chose midwifery as their $2^{\text {nd }}$ and $3^{\text {rd }}$ choice and that midwifery was not the first choice of any of them. In another study conducted on the midwifery students, it was detected that midwifery was the $2^{\text {nd }}$ and $3^{\text {rd }}$ choice of a part of them (18.7\%) and not the first choice of any of them (Pinar et al, 2013). In addition to these results, half of the students in this study preferred this department because of the ease of finding a job. In another study conducted with student-midwives, it was determined that the students chose their occupation willingly (Pınar et al, 2013; Yurtsal et al, 2014; Bilgin et al, 2016; Yücel et al, 2018; Kartal and Yazıc1, 2017), and supporting this study, the most determining factor in choosing the midwifery department was the ease of finding a job (Orak et al, 2008; Erkal et al, 2012; P1nar2013; Yurtsal et al, 2014; Bilgin et al, 2016). A statistically significant difference was found between the occupational professionalism attitudes of the students according to the reason for choosing the occupation $(p<0.05)$ (Table 2). This difference is caused by the high scores of the students who chose midwifery as an occupation for the purposes of easily finding a job. It was detected in the study that there was a statistically significant difference between the occupational professionalism attitudes of the students according to their ages $(p<0.05)$ and that students between the ages of 19 and 22 had higher scores of occupational professionalism attitude (Table 1). The students between the ages of 19 and 22 consisted of students in their $2^{\text {nd }}$ and $3^{\text {rd }}$ year. Thus, a statistically significant difference was found in the occupational professionalism attitudes of the students according to their grade levels $(p<0.05)$ (Table 1). As the occupational application experiences of the students increased, their professional value perception increased in parallel. In our study, the professional attitudes of the $2^{\text {nd }}$-year midwifery students were found to improve in the subsequent years. Similarly, in studies conducted on midwifery students, professional value perception and attitudes change as the school year changes (Pınar et al, 2013; Yücel et al, 2018). We believe that as students' grade year increases throughout their training, the number of classes on occupation-specific courses increases, and thus, their professional attitudes improve accordingly.

In this study, more than half of the parents of the students were found to be primary school graduates. In the studies conducted on midwifery students in Turkey, the education levels of the parents of the students were found similarly to be at a low level (Pınar et al, 2013; Yurtsal et al, 2014; Y1ldırım et al, 2014; Yücel et al, 2017; Yücel et al, 2018). A statistically significant difference was detected between the occupational professionalism attitudes of the midwifery students according to the place where they lived with their parents and the perceived income level $(\mathrm{p}>0.05)$ (Table 1). This difference was caused by the scores the students living in the city and the scores of the students who perceived their income at the middle-income level as being higher. A large majority of the student-midwives find the midwifery occupation appropriate for themselves. In studies conducted on midwifery students studying in different cities, the students defined midwifery as an occupation appropriate for themselves (P1nar et al, 2013; Kartal and Yazıc1, 2017; Yücel et al, 2018). A statistically significant difference was found between the occupational professionalism attitudes of the midwifery students according to whether they found the occupation appropriate for themselves $(\mathrm{p}>0.05)$ (Table 2). This difference was caused by the low score of the ones who did not find the midwifery occupation appropriate for themselves.

Application fields and the extent of these applications are important in the midwives showing constant professional development. Thus, there is a requirement for the students to pass through theoretical learning and practical application during the training period in Turkey (Casey et al, 2017). The success of the healthcare service is dependent on the care providing midwives' going through a quality training process (Merih and Arslan 2012). When studies on this subject are reviewed, it can be seen that in what is similar to our study, the thoughts of students on midwifery become more positive after receiving training than they were in the period before training (Beydağ et al, 2008; Bilgin and Ocakç1, 2011; Pınar et al, 2013; Yurtsal et al, 2014; Yücel et al, 2018; Bilgin et al, 2016). In this study, a statistically significant difference was found between the approach toward the occupation of student-midwives after starting training and their occupational professionalism attitudes $(\mathrm{p}<0.05)$ (Table 2). This difference was caused by the exceptionally low scores of those with negative thoughts toward the occupation after the studentmidwives began their education.

Since the number of studies on professionalism in midwifery is a little small in Turkey, the studies measuring the professional attitudes of midwifery students through different scales were compared with 59 | P a g e 
this study because in recent years, the interest in professionalism in the field of midwifery has increased in Turkey. In the study by Pinar et al. (2013) conducted with midwifery students using the same scale, the mean IPAO score was found to be high similar to this study. Yücel et al. (2018) used the "Midwifery Professional Values Scale" and found the level of professional value perception of the midwifery students to be high. In the present study, more than half of the students stated that they wanted to work as a midwife after graduation. Occupation-specific application fields throughout training help students acquire professional values. Thus, the correct employment of midwives is particularly important in the development of professional values after graduation. In another study conducted with midwifery students, in what is similar to our study, it was detected that most of the students want to work as midwives and that the rest wanted to become academics (P1nar et al, 2013; Yurtsal et al, 2014; Kartal and Yazıc1, 2017; Yücel et al, 2017; 3, Yücel et al, 2018). The existence of postgraduate training programs in the midwifery departments of universities is considered to be a factor motivating students who study at such universities toward academia.

\section{Conclusion}

In conclusion, professional attitudes of midwifery students were found to be at a high level. It is recommended that motivation programs, meetings, and seminars be given to student-midwives who chose the occupation unwillingly and believe it is not an occupation fitting them and that the concepts that can help the occupational adaptation of the students regarding professionalism be included in the syllabus. It is also recommended that further studies be conducted to understand the occupational value of the occupation of midwifery with larger samples.

\section{References}

Adıgüzel, O., Tanrıverdi, H., Sönmez Özkan, D. (2011). Occupatıonal professıonalısm and the case of nurses as the members of the profession. Journal of Administrative Sciences, 9(2),237-259.

Beydağ, K.D., Gündüz, A., Gök Özer, F. (2008). The view of Denizli health college students about their educations and their professional expectations. Pamukkale Medical Journal, 1(3),137-142.

Bilgin, Z., Ocakç1, A.F. (2011). The professional motivation of midwifery students, Journal of Anatolia Nursing and Health Sciences, 14(3), 40-46.

Bilgin, Z., Özkan, H.A., Baş, M. (2016). Effects of motivation level the midwifery students in clinical practice expectations. Online Journal of Turkish Health Sciences, 1(2),38-53.

Casey, M., Cooney, A., Connel, R., et all. (2017). Nurses', midwive and key stakeholders' experiences and perceptions on requirements to demonstrate the maintenance of professional competence. Journal of Advanced Nursing, 73(3),653-664.

Erbil, N., Bakır, A. (2009). Developing inventory of professional attitude at occupation. Journal of International Human Sciences, 6(1),290-302.

Ergin, B.A., Özcan, G.M., Acar, Z., Ersoy, N., Karahan, N. (2011). National midwifery codes project. I. International \& II. National Midwifery Congress, 15-20.

Erkal, İ.S., Yalçın, A.S., Sancar, B. (2012). Ankara unıversıty faculty of health sciences students' reasons for selectıng midwifery and nursing divisions. Journal of Ankara Health Sciences, 73-90.

Gökçora, İ.H. (2005). Concepts of professional and professionalism, concerning our social lives and the turkish scientific World. The World Of Information, 6(2), 237-250.

Güner, S., Yurdakul, M., Yetim, N. (2015). Academic perspective on the issues reflect a qualitative study of midwifery profession in Turkey. Journal of Higher Education \& Science, 5(1), 80-87.

$60 \mid \mathrm{P}$ a g e

www.iiste.org 
Halldorsdottir, S., Karlsdottir, S.I. (2011). The primacy of the good midwife in midwifery services: an evolving theory of professionalism in midwifery. Scand J Caring Sci, 25,806-817.

Kacaroğlu Vicdan, A. (2010). Professionalism in nursing, Maltepe University Journal Of Nursing Science And Art, Symposium Special Issue, 261-263.

Karadağ, A., Hisar, F., Özhan Erbaş, V. (2004). Behavioral inventory related to professionalism in nursing. Journal of Nursing Forum, 7(4),14-22.

Karaman, Ö.E., Okumuş, H. (2015). The self-assessments of midwifery students by job descriptions and competency areas. Journal of Anatolia Nursing and Health Sciences, 18(3),189-195.

Kartal, Y.A., Yazic1, S. (2017). The determination of anxiety and stress levels of midwifery students begining the first clinical experience and post-experience period. HSP, 4(3), 190-195.

Merih, Y.D., Arslan, H. (2012). Job satisfaction levels of nurses and midwives and their 1deas about professional awareness and professional organizations. The Journal Of Education And Research In Nursing, 9(3),40-46.

Orak, N., Alpar, Ş. (2012). Validity and reliability of the nurses' professional values scale's turkish version, Journal of Marmara University Institute of Health Sciences, Supp.(1), 22-30.

Orak, S., Orhan, H., Ağırman, Ö., Özgürce, B. (2008). Süleyman demirel university model in nursemidwife education: Isparta health collage ýntern students knowledge and behavior about in integrated application in clinical field. Journal of Süleyman Demirel University Faculty of Medicine, 15(3),11-16.

Pınar, Ş.E., Cesur, B., Duran, Ö., et al. (2013). Analysis of occupational professionalism of midwifery students and affecting factors. Journal of Firat Health Services, 8(23),19-37.

Sabanc1oğulları, S., Doğan, S. (2012). Professional 1dentity development and nursing, Journal of Anatolia Nursing and Health Sciences, 15(4), 275-282.

Seçer, Ş. (2009). Constituting the model of occupational life and its uses in occupational analysis. Journal of Social Sciences, 7(1),35-56.

Secrest, J.A., Norwood, B.R., Keatly, V.M. (2003). I was actually a nurse: the meaning of professionalism for baccalaureate nursing students. Journal Of Nursing Education, 42(2),77-82.

Yıldırım, F., Çelik, P., Özmen, C., et all. (2014). Midwifery students's views on involving men midwife in midwifery profession. Gümüşhane University Journal Of Health Science, 3(1),646655.

Yücel, U., Oran, N.T., Yüksel, E. (2017). Evaluation of midwifery students' opinions of their profession and assessment of their preferences about institution types that they will work. Gümüşhane University Journal Of Health Sciences, 6(4),69-76.

Yücel, U., Ünal, İ., Özdemir, T., et al. (2018). Determınatıon of professional value perceptıns of midwifery students. Medical Sciences, 13(4),95-105.

Yurtsal, Z.B., Biçer, S., Duran, Ö., et al. (2014). Faculty of health science midwifery 1st and 4th class undergraduate students determination on the views of profession. Journal of Erciyes University Faculty of Health Sciences, 2(2), 15-25. 